\title{
The future of nuclear cardiac imaging: Reflection and a vision
}

\author{
Ami E. Iskandrian, MD, MACC, MASNC \\ a Division of CV Diseases, Department of Medicine, University of Alabama at Birmingham, \\ Birmingham, AL
}

Received Oct 2, 2017; accepted Oct 2, 2017

doi: 10.1007/s12350-017-1088-4

My editor's page will be excerpts from my plenary lecture given at the International Conference on Nuclear Cardiology and Cardiac CT, Vienna, Austria, on May 7, 2017.

It was indeed a pleasure and an honor to address the audience of this meeting, which has a track record of $>20$ years bringing people from around the world to learn and share knowledge.

The predictions are that in the United States by 2035 , > 123 million will have hypertension; $>24$ million will have coronary artery disease $(\mathrm{CAD}) ;>11$ million will have had a stroke; $>9$ million will have heart failure; and $>7$ million will have atrial fibrillation. That adds to a projected increase in heart disease costs are to double from $\$ 555$ billion in 2016 to $\$ 1.1$ trillion in 2035! One would predict similar increases in both developed and developing countries although Sweden recently reported considerable declines in death from any cause, death from cardiovascular disease, death from coronary heart disease, and hospitalization for cardiovascular disease between 1998 and 2014 in both general population and in those with diabetes mellitus. ${ }^{1}$ This change and other changes (Table 1) imply that imaging in general, and nuclear imaging especially will continue to be a popular imaging modality for sometimes to come.

It is very likely that positron emission tomography (PET) use and measurement of myocardial blood flow (MBF) will increase. A recent study may shed some light, women though having less severe CAD by coronary angiography than men, had worse outcome especially those with reduced coronary flow reserve

Reprint requests: Ami E. Iskandrian, MD, MACC, MASNC, Division of CV Diseases, Department of Medicine, University of Alabama at Birmingham, 318 LHRB/ 1900 University BLVD, Birmingham AL 35294; aiskand@uab.edu

J Nucl Cardiol 2018;25:1-5.

$1071-3581 / \$ 34.00$

Copyright (C) 2017 American Society of Nuclear Cardiology. ratio (ratio of hyperemic to rest MBF) measured by PET. $^{2}$ Historically, the prominent physician from University of Paris wrote in 1902 "Another point to remember is that angina pectoris is, like gout, a disease of men, and not women. When it does manifest itself in females, as is occasionally the case, it is often so confused with the common and frequent pains in the left side, due to flatulence or other causes, to which that sex is especially prone, that its recognition may be a matter of some difficulty." His views were probably shared until very recently by many physicians!

Though MBF use will increase (Figure 1), it does not mean that all problems have been solved such variability in measurements. Kitkungvan et al reported test-retest methodological precision of global PET myocardial perfusion by serial rest performed within minutes apart is $\pm 10 \%$ while the day-to-different-day biological plus methodological variability was $\pm 21 \%$. Further, the global myocardial perfusion at 8 minutes after 4 minutes dipyridamole infusion was $10 \%$ higher than at standard 4 minutes after dipyridamole. ${ }^{3}$ The editorial by Beanlands concluded "... ultimately the value of flow quantification must be shown in multicenter clinical trials." 4 Dilsizian et al concluded "...trust the quantitative analysis but verify it by visual analysis." ${ }^{, 5}$ Clearly more studies are needed to address the variability and impact of using different hardware, software, stress agent, and protocol.

In additions to the tracers in Figure 1 and other tracers to study cardiac metabolism and innervation, there are a host of newer tracers; a partial list is provided in Table 2 and many of these are presented in this meeting. What is encouraging in the new list is that these tracers will expand the use of nuclear imaging in other cardiac conditions such as acute coronary syndromes, myocarditis, chemotherapy-related cardiotoxicity, and valvular heart diseases.

As we move forwards, it is equally important to remain grounded and acknowledge the achievements 
Table 1. Nuclear imaging in the future

Increasing acceptance of the newer generation of imaging systems and softwares

Increasing utilization of PET in ischemic heart diseases

Detection of CAD

Patient management

Outcome

Viability assessment

Evaluation of the physiology and implications of micro-vascular (small vessel disease; endothelial dysfunction, etc.)

Increasing use of PET in non-ischemic heart diseases

Infiltrative disorders

Inflammatory diseases

Infections (valves, prosthetic valves, pace maker and ICD leads and pockets)

Increasing use of hybrid imaging (Sequential with 2 imaging systems or simultaneous with one imaging system)

PET + CTA or CAC

SPECT + CTA or CAC

PET/MRI

18F- Flurpiridaz will be approved by the Food and Drug Administration in the United States and will have a wide appeal globally (if price is right!)

There will be newer applications in other heart diseases:

Cardiomyopathies

Arrhythmias/Sudden death

Acute Coronary Syndromes

Pulmonary hypertension

RV function (+ LV function)

Congenital HD and coronary anomalies in adults

Molecular imaging

\section{Positron Emission Tomography: Tracers}

\begin{tabular}{|l|l|l|l|l|l|l|}
\hline Tracer & Use & $\begin{array}{l}\text { T1/2 } \\
\text { min }\end{array}$ & Feature & $\begin{array}{l}\text { FDA } \\
\text { approved }\end{array}$ & $\begin{array}{l}\text { Use } \\
\text { with } \\
\text { exercise }\end{array}$ & $\begin{array}{l}\text { Use outside } \\
\text { cardiology }\end{array}$ \\
\hline Rubidium-82 & Perfusion \& MBF & 1.25 & Generator & Yes & No & No \\
\hline $\begin{array}{l}\text { N-13- } \\
\text { Ammonia }\end{array}$ & Perfusion \& MBF & 9.96 & $\begin{array}{l}\text { On-site } \\
\text { cyclotron }\end{array}$ & Yes & No & No \\
\hline $\begin{array}{l}\text { O-15- } \\
\text { Water }\end{array}$ & Perfusion \& MBF & 2.06 & $\begin{array}{l}\text { On-site } \\
\text { cyclotron }\end{array}$ & $\begin{array}{l}\text { No } \\
\text { (Europe) }\end{array}$ & No & No \\
\hline $\begin{array}{l}\text { F-18- } \\
\text { Flurpiridaz }\end{array}$ & Perfusion \& MBF & 110 & $\begin{array}{l}\text { Unit dose } \\
\text { (regional } \\
\text { cyclotron) }\end{array}$ & $\begin{array}{l}\text { 2nd Phase-3 } \\
\text { trial }\end{array}$ & Yes & No \\
\hline $\begin{array}{l}\text { F-18- } \\
\text { FDG }\end{array}$ & Metabolism & 110 & $\begin{array}{l}\text { Unit dose } \\
\text { (regional } \\
\text { cyclotron) }\end{array}$ & Yes & NA & $\begin{array}{l}\text { Yes } \\
\text { (Oncology) }\end{array}$ \\
\hline
\end{tabular}

Figure 1. The common PET tracers for clinical applications. 
Table 2. Partial list of new tracers and applications

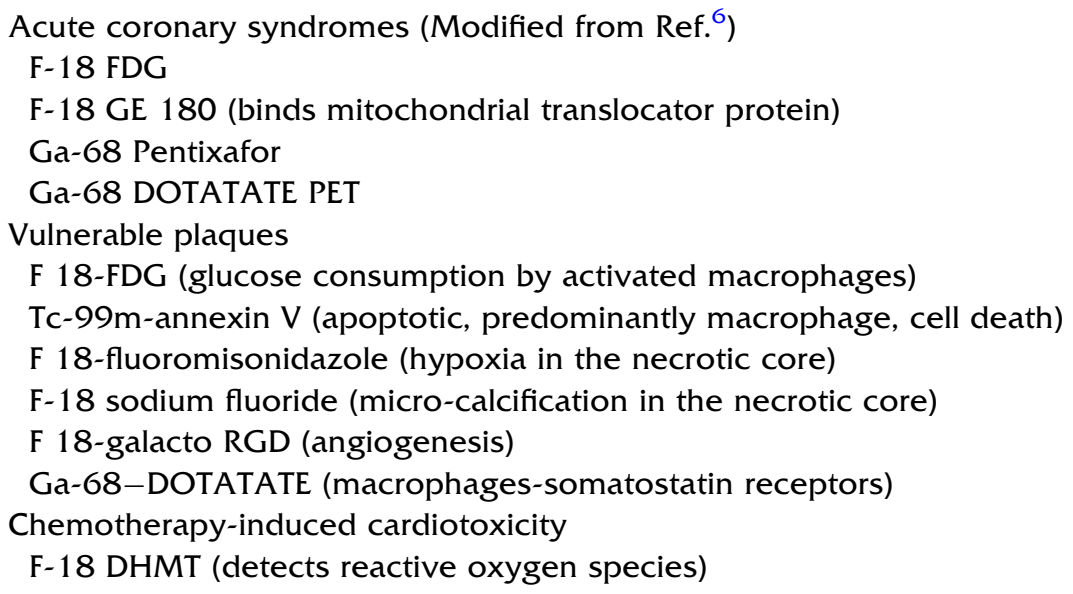

Table 3. A partial list of Nobel Laureates in physics and chemistry who contributed to nuclear medicine (courtesy of $\mathrm{H}$ William Strauss, MD). The number between parenthesis is the year the Award was received

Marie and Pierre Curie (1903, 1911): Radioactive decay (Radium)

Henri Becquerel (1903): natural radioactivity (Uranium)

Albert Einstein (1921): Relation of matter to energy

Arthur Compton (1927): Scatter of radiation; Compton effect

Paul Dirac (1933): predicted existence of the positron (theoretical)

Carl Anderson (1936): detected antimatter (positron)

Ernest Lawrence (1939): Cyclotron

Georg von Hevesy (1943): tracer principles

John Cockcroft (1951): Linear accelerator

Emilio Serge (1959): Technetium

Robert Hofstadter (1961): Na-I scintillation detector

Henry Taube (1983): inorganic chemistry (technetium)

and shortcoming of past performances. Table 3 provides a partial list of Noble laureates (courtesy of $\mathrm{H}$ William Strauss, MD) and their contributions. On the downside, Table 4 provides a partial list of products we studied but faded away!

It is likely that future research will be more complex and demanding as it will require comparative cost-effectiveness and hence involvement of broader presentation of share-holders. Boden and Meadows concluded "The need for updated models of risk in this era of low event rates; a broader understanding of CAD beyond the prevailing paradigm of obstructive epicardial CAD; inclusion of novel, patient-centered and efficiency outcomes; and the need for evidence of optimal post-test treatment. Given the inherent variability in patient phenotypes and clinical presentations, there is a compelling need to translate group data derived from randomized clinical trials to individual patient management, such as distinguishing between modifiable and non-modifiable risk factors, accounting for competing comorbidities, and better defining patient-centered measures." 7

The ACC/AHA and ESC guidelines and appropriateness use criteria deserve are slowly but surely changing to reflect recent evidence-based findings. ${ }^{8-13}$ Stirrup et al summarized the similarities and differences 
Table 4. A partial list of products that were tested but were not long-lasting

Tc-99m teboroxime

Tc-99m N-NOET

I-123 IPPA

I-123 BMIPP

Tc-99m Glucarate (AMI scan)

Tc-99m-Annexin-V

Ambulatory nuclear detector (VEST)

Multi-crystal gamma camera

Multiwire proportional gamma camera

First pass RNA

Stress agents

Arbutamine

Selective a-2 agonists (ATL146e, MREO470, CGS2 1680) between the 2 with regard to the utilization of imaging. ${ }^{14}$ There were two editorials in response to this report. ${ }^{15,16}$ Excerpts from the report by Christian are shown in Table 5 .

Finally, my reflections and conclusions as to the future are summarized in Table 6.

In summary, the anticipated increase in number of patients with ischemic heart disease in the future, the expanded role of nuclear imaging in non-ischemic heart diseases, the use of PET imaging and MBF, and the availability of newer tracers, hardware and software are only few of the reasons to be optimistic about the future of nuclear cardiac imaging. Lessons learned from the past experiences and newer guidelines and position papers and statements are important. It is likely that future studies are going to be more complex and demanding and require broad participation of broader spectrum of shareholders as well as across Atlantic cooperation.

Table 5. ACC/AHA and ESC guidelines for myocardial revascularization in stable patients

The Guidelines have an important role in the economics and practice of medicine in the USA

The Bayesian principles of pre-test likelihood of CAD are used in both guidelines; George Diamond must be

pleased to see they are the corner stones of the many guidelines $\sim 40$ years later!

Both guidelines emphasize the medical approach as first line therapy; Thanks to COURAGE trial

The USA is largely a fee for service enterprise (though it is changing!)

There is variability in the degree of socialization between European countries

In USA, increasingly hospitals are the dominant force in health care

Hospitals control the majority of physician practices and wield significant influence on physician behavior Slight bias to perform coronary angiography for many intermediate- and high-risk patients in AHA/ACC guidelines In 2011 , when most of the guidelines were written, the highest fees for physicians and hospitals are in the cardiac catheterization lab

Guidelines in the grey zones retain flexibility in practice

Table 6. Reflections and conclusions

There is a need for a scientific oversight "committee" to work with sponsors on future study designs

The study design and end-points are likely to be more complex and demanding

Comparative-effectiveness research requires a broad representation of shareholders

The goals should be set for long-term rather than short-term gains

The aim should be in the best interest of the field rather than individuals

There should be across Atlantic participation in these efforts

Industry and sponsors should understand that what is best for imaging in general is best for each as well; we grow together

There should be organized efforts to raise necessary funds to pursue creative research (philanthropy, industry, investors, and government agencies)

We need to promote the field world-wide and be inclusive

There are real reasons to be optimist for the future of our field 
Ami E. Iskandrian, MD, MASNC
Editor-in-Chief

\section{Disclosures}

None related to this presentation but the author is unpaid consultant to Lantheus Pharma and is a Member of the Imaging committee: GE-ADMIRE-ICD Trial

\section{References}

1. Rawshani A, Rawshani A, Franzén S, et al. Mortality and cardiovascular Disease in type 1 and type 2 diabetes. N Engl J Med. 2017;376:1407-8.

2. Taqueti Viviany R, Shaw Leslee J, et al. Excess cardiovascular risk in women relative to men referred for coronary angiography is associated with severely impaired coronary flow reserve, not obstructive disease. Circulation. 2006. doi:10.1161/ CIRCULATIONAHA.116.023266.

3. Kitkungvan D, Johnson NP, Roby AE, et al. Routine clinical quantitative rest stress myocardial perfusion for managing coronary artery disease. JACC. 2017;10:565-77.

4. Beanlands RS, Chong AY, deKemp RA. Clinical PET flow reserve imaging, is there precision to treat patients or populations? JACC. 2017. doi:10.1016/j.jcmg.2016.10.004.

5. Dilsizian V, Chandrashekhar Y, Narula J. PET myocardial blood flow "Trust, But Verify". JACC. 2017. doi:10.1016/j.jcmg. 2017.03.006

6. Strauss HW, Narula J. Imaging vulnerable plaque a medical necessity or a scientific curiosity? J Am Coll Cardiol. 2017. doi: 10.1016/j.jacc.2017.03.005.
7. Boden WE, Meadows JL. Role of imaging in the management of stable ischemic heart disease; an evolving paradigm shift. JACC. 2017. doi:10.1016/j.jcmg.2016.12.009.

8. Windecker S, Kolh P, Alfonso F, et al. 2014 ESC/EACTS guidelines on myocardial revascularization. Eur Heart J. 2014;35:2541-9.

9. Fihn SD, Gardin JM, Abrams J, et al. 2012 ACCF/AHA/ACP/ AATS/PCNA/SCAI/STS guideline for the diagnosis and management of patients with stable ischemic heart disease. J Am Coll Cardiol. 2012;60:e44-164.

10. Fihn SD, Blankenship JC, Alexander KP, et al. 2014 ACC/AHA/ AATS/PCNA/SCAI/STS focused update of the guideline for the diagnosis and management of patients with stable ischemic heart disease. J Am Coll Cardiol. 2014;64:1929-9.

11. Greenland P, Alpert JS, Beller GA, Benjamin EJ, Budoff MJ, Fayad ZA, et al. 2010 ACCF/AHA guideline for assessment of cardiovascular risk in asymptomatic adults. Circulation. 2010;122:e584-636.

12. Levine GN, Bates ER, Blankenship JC, et al. 2011 ACCF/AHA/ SCAI guideline for percutaneous coronary intervention. J Am Coll Cardiol. 2011;58:e44-122.

13. Hillis LD, Smith PK, Anderson JL, et al. 2011 ACCF/AHA guideline for coronary artery bypass graft surgery. J Am Coll Cardiol. 2011;58:e123-210.

14. Stirrup J, Velasco A, Fadi H. Guidelines in review: comparison of ESC and ACC/AHA guidelines for myocardial revascularization. J Nucl Cardiol. 2017;24:1046-3.

15. Petretta M, Cuocolo A. Comparison of ESC and ACC/AHA guidelines for myocardial revascularization Are the differences clinically relevant? The European perspective. J Nuc Cardiol. 2017;24:1057-1.

16. Christian T. The unsaid word. J Nucl Cardiol. 2017;24:1054-6. 